\title{
Multiple Myeloma with Pleural Effusion According to Initial Findings
}

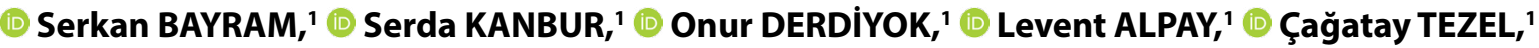 \\ (D) Volkan BAYSUNGUR'
}

'Department of Thoracic Surgery, Süreyyapaşa Chest Diseases and Thoracic Surgery Training and Research Hospital, İstanbul-Turkey

\begin{abstract}
SUMMARY
Primary malignant myelomatous pleural effusion (PMMPE) occurs in $<1 \%$ of patients with multiple myeloma (MM) and is diagnosed by the appearance of plasma cells on cytology or by positive flow cytometry. The nucleus-to-cytoplasm ratio is high. In addition, immature plasma cells with the presence of nucleus, Mott cells, and Russell bodies are independent poor prognostic factors. Clinicians should be able to distinguish between PMMPE and secondary pleural effusions because PMMPE is significantly associated with poor prognosis and poor survival. Presently described is a case diagnosed as MM after pleural sampling and parenchymal wedge resection performed with video-assisted thoracoscopic surgery for pleural effusion.

Keywords: Mutiple myeloma; pleural effusion; video-assisted thoracoscopic surgery.

Copyright $\odot$ 2018, Turkish Society for Radiation Oncology
\end{abstract}

\section{Introduction}

Multiple myeloma (MM) is a neoplastic disease caused by a single plasma cell proliferation and is associated with monoclonal immunoglobulin production. MM is a rare disease involving non-reticuloendothelial tissues that can cause pleural effusion. Myelomatous etiology is usually diagnosed if pleural fluid protein electrophoresis demonstrates gammopathy or if atypical plasma cells are present in abundant quantity on pleural fluid cytology.[1] MM accounts for approximately $10 \%$ of all hematologic cancers. It usually causes clinical manifestations such as anemia, bone pain, hypercalcemia, renal insufficiency, and infections due to excessive proliferation of immunoglobulins and cytokines with overproduction of $\operatorname{IgG}$ and $\operatorname{IgA}$ monoclonal proteins. [2] MM diagnosis after pleural effusion is established by the increase of monoclonal proteins on pleural pro- tein electrophoresis, increase of plasma cell quantity in pleural fluid, and presence of atypical plasma cells on pleural biopsy. In this study, parenchymal and pleural involvement in MM was detected in a patient with pleural effusion and the case is presented in the light of the literature.

\section{Case Report}

A 64-year-old male patient was admitted to our clinic with complaints of dyspnea and fatigue that had been persistent for a month. Although no remarkable personal or family history was noted, the patient had been smoking 40 packets of cigarettes per year. On physical examination, fever was $36.7^{\circ} \mathrm{C}$, pulse rate was 100 beats/min, respiratory rate was 22 breaths/min, and arterial blood pressure was $130 / 85 \mathrm{mmHg}$. In the right hemithorax, matite was detected under the scapula on percussion, whereas auscultation revealed a decrease in 


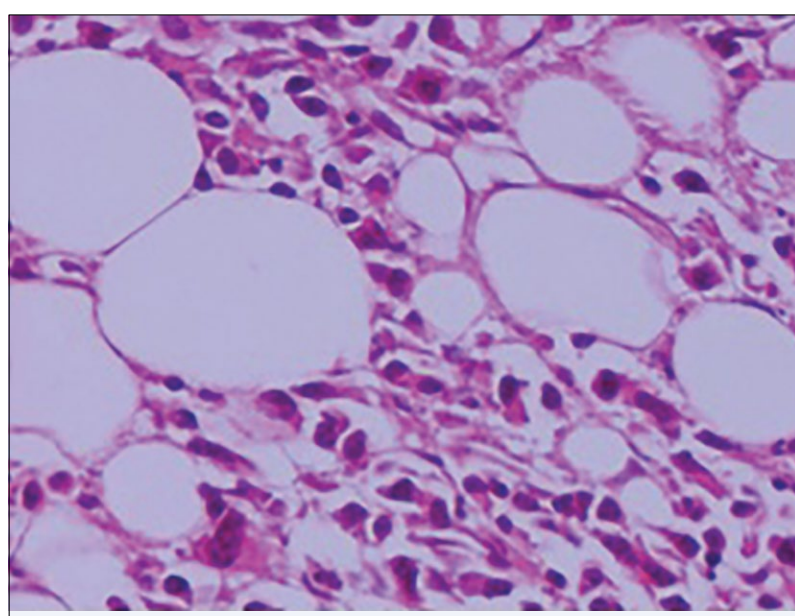

Fig. 1. Density enhancement in the right hemithorax sub-zone of the postero-anterior chest X-ray with pleural fluid.



Fig. 2. (a) Hematoxylin-eosin staining. Plasma cells with atypical features at a site where erythrocytes are present.

respiratory sounds in the lower right zone. Postero-anterior chest X-ray revealed pleural effusion in the lower hemisphere of the right hemithorax (Fig. 1). Computed tomography of the thorax showed no parenchymal lesions or pleural and bony lesions. Biochemical parameters were normal. Increased gamma globulin level was observed on serum protein electrophoresis. Sampling was done via thoracentesis. The sample fluid was negative for acid-resistant bacilli, 26\% for lymphocytes and $74 \%$ for leukocytes. There were 3 malignant cells observed at $500 \mathrm{~mm}^{3}$ magnification. There was no growth in nonspecific culture. On biochemical examination of the liquid, the following levels were obtained: albumin, $2.4 \mathrm{~g} / \mathrm{dL}$ (blood: 3.6), total protein $3.02 \mathrm{~g} / \mathrm{dL}$

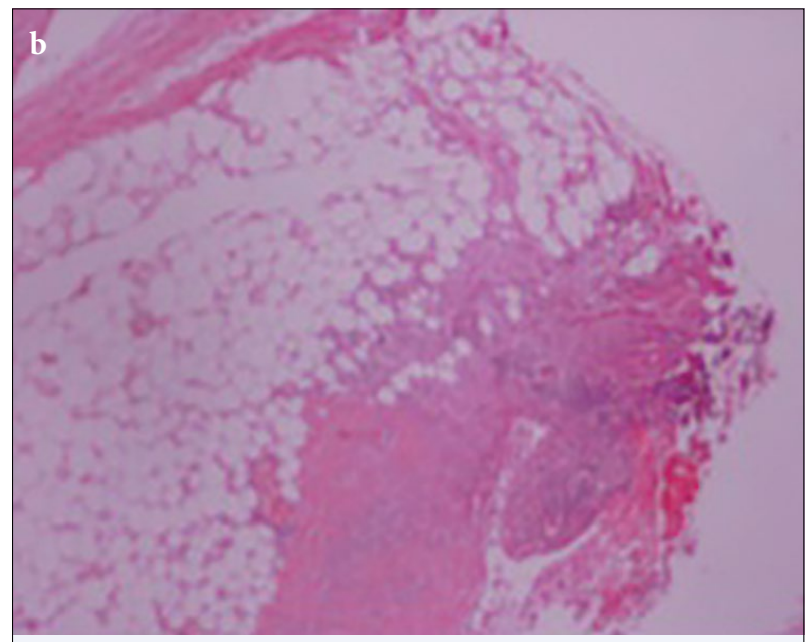

Fig. 2. (b) Atypical plasma cells with concentric nuclei.

(blood: 7.1), LDH 331 U/L (blood: 160), ADA 12.50 U/L (blood: 24.4). When the pathology reported an atypical cell, decision was made to operate. Pleural biopsy and parenchymal wedge with video-assisted thoracoscopic surgery were performed. The pathology result was reported as plasma cell neoplasia. Pleural involvement in MM was reported according to the bone marrow biopsy result (Fig. 2). The patient was directed to the oncology department for systematic chemotherapy. No pathology was observed during the 14-month follow-up.

\section{Discussion}

MM is mainly characterized by bone marrow, blood, and monoclonal immunoglobulins in the urine, malignant plasma cells in osteoporosis, and osseous lesions. [3] MM is a neoplastic disease that causes the proliferation of transformed B lymphoid progenitor cells.[4] MM accounts for $1 \%$ of all malignancies and approximately $10 \%$ of all hematologic cancers. Pleural effusion occurs in approximately 6\% of MM patients.[5] MM mainly affects bone marrow cells. But in rare cases, the first finding is pleural effusion. [6] Only pleural involvement is reported in very few patients without cavitary or mass lesions. Lytic lesions are frequently seen with the involvement of the chest wall, mediastinum, or pulmonary parenchyma.[7] In cases of pleural involvement, immunoglobulin is secreted by malignant plasma cells, usually caused by pleural fluid formation due to an increase in colloid osmotic pressure that cannot be absorbed.[8] Approximately 25\% of MM cases are of IgA type. However, $>50 \%$ of cases of multiple myeloma with osteo involvement are of the IgA type and are especially seen in serological spaces. [9] Our case had 
IgG-type MM with pleural involvement and pleural effusion. Causes of pleural effusion in MM include heart failure, renal failure, and amyloidosis. The exclusion of pleural fluid distinguished these cases. Over $10 \%$ of the plasma cells in the bone marrow were diagnostic for multiple myeloma. In studies, the diagnostic value of MM plasma infiltration using a pleural biopsy has been very low.[10]

\section{Conclusion}

In conclusion, plasma cell neoplasms should be considered in the differential diagnosis of pleural effusions. As a result, MM pleural effusion is very rare and may be the first finding.

Peer-review: Externally peer-reviewed.

Conflict of Interest: None declared.

Authorship contributions: Concept - S.B.; Design - S.B.; Supervision - S.K.; Data collection \&/or processing - O.D.; Analysis and/or interpretation - L.A.; Literature search S.K.; Writing - O.D., S.B.; Critical review - Ç.T., V.B.

\section{References}

1. Zhang LL, Li YY, Hu CP, Yang HP. Myelomatous pleural effusion as an initial sign of multiple myeloma-a case report and review of literature. J Thorac Dis 2014;6(7):E152-9.

2. Munshi NC, Longo DL, Anderson KC. Multiple myeloma. In: Fauci AS, Kasper DL, Longo DL, Braunwald
E, Hauser SL, Jameson JL, editors. Harrison's hematology and oncology. 17th ed. 2008. p. 206-7.

3. Klanova M, Klener P, Trneny M, Straub J, Spicka I. Intrapleural bortezomib for the therapy of myelomatous pleural effusion: a case report. Case Reports Immunol 2012;2012:978479.

4. Kapadia SB. Multiple myeloma: a clinicopathologic study of 62 consecutively autopsied cases. Medicine (Baltimore) 1980;59(5):380-92

5. Natori K, Izumi H, Nagase D, Fujimoto Y, Ishihara S, Kato $\mathrm{M}$, et al. IgD myeloma indicated by plasma cells in the peripheral blood and massive pleural effusion. Ann Hematol 2008;87(7):587-9.

6. Chang H, Chou WC, Lee SY, Huang JY, Hung YH. Myelomatous pleural effusion in a patient with plasmablastic myeloma: a case report. Diagn Cytopathol 2009;37(3):205-7.

7. Pacheco A, Perpiñá A, Escribano L, Sanz I, Bellas C. Pleural effusion as first sign of extramedullary plasmacytoma. Chest 1992;102(1):296-7.

8. Manley R, Monteath J, Patton WN. Co-incidental presentation of IgA lambda multiple myeloma and pleural involvement with IgM kappa non-Hodgkin's lymphoma. Clin Lab Haematol 1999;21(1):61-3.

9. Sasser RL, Yam LT, Li CY. Myeloma with involvement of the serous cavities. Cytologic and immunochemical diagnosis and literature review. Acta Cytol 1990;34(4):479-85.

10. Rodríguez JN, Pereira A, Martínez JC, Conde J, Pujol E. Pleural effusion in multiple myeloma. Chest 1994;105(2):622-4. 